\title{
Locating the Social Position of Pakistani Women in Text Books
}

\author{
* Dr. Ikram Badshah, Assistant Professor \\ ** Dr. Sarfraz Khan, Assistant Professor (Corresponding Author) \\ *** Muhammad Kamran, PhD Scholar
}

\begin{abstract}
The curriculum is the most grounded device to transmit and transform the way of life, values, and convictions of the society to the students. At the point the children enter the school, the pictures of the male and female depicted in books, solidify their ideas about gender bias and such gender stereotypes shape the mental framework of the students and leave an everlasting effect on the social outlook of the students. Children develop a certain sense of perception and personality while reading such books. The text, words, and pictures in the books leave a permanent blueprint in their mind and they organize their behavior along the patriarchal line, represented in the books. In the textbooks, maledominant ideology has been used to construct reality in such a way that serves the interest of men in a society. There is a latent and manifest nexus of power and language which favors the patriarchal values. Gender ideologies apparent in the books are also embedded in children's pictures, mass media, and even clothing. There are also more males characters and heroes than females characters and heroes in the textbooks of Urdu and English. All prominent leaders of the Pakistan movement are males and only one female leader, Fatimah Jinnah, has representation in the books but that too in her capacity as sister of the founder of Pakistan Quaid-i-Azam Muhammad Ali Jinnah.
\end{abstract}

Keywords: Gender, Text Books, Content Analysis, Pakistan

\section{Introduction}

Gender roles have been constructed through the socialization process. Gender roles are not inherited but acquired through the nexus of culture and societal institutions like education. In our society, gender is structured in a manner that boys are taught to be tough, resilient, and dominant to grow into men. They are fortified by their families and schools to be competitive, sturdy, and robust (Lawson, Crouter \& Mchale, 2016). In former times, informal education had played a key role in disseminating traditional gender roles. Over time, formal education has outshined informal education in perpetuating gender identities from generation to generation. However, the role of content has been underestimated in the construction of gender identities and concomitant moralities. The modern content is making sure to produce conformists rather than free thoughts intellectuals.

The course books chosen to be analyzed were part of the textbooks published and developed by The National Book Foundation as Federal Textbook Board. The books chosen were of the subjects, Urdu, and English of grade five, six, and seven. The reason for the analysis of textbooks is since the curriculum is the most grounded device to promulgate the way of life, values, and convictions of society to the student. The curriculum is executed through the reading and learning material and the environment of the school, known as the covered up or hidden curriculum. Since each general public has its conviction, framework, and ideology, the same are reflected and depicted in the curriculum.

Textbooks leave an enduring image in the minds of young children, who begin to identify themselves with characters and their roles already stated in the contents of the textbook. Further, children view their world (experiential reality) and the world outside through textbooks. Thus, along with teachers, textbooks help in shaping children's attitudes, behaviors and beliefs. In other words, the hidden messages children get through textbooks' texts and illustrations and their transmission by the teachers contribute to shaping their attitudes and behavior patterns from a very early age. The selfinvented social realities like gender construction and gender roles are embedded in our textbook boards in a way that it buried reality from the eyes of students. They unconsciously receive those hidden gender meanings lies in text induces gender inequity in society. Being a patriarchal society, the

* Department of Anthropology, Quaid-i-Azam University Islamabad Email: ikram@qau.edu.pk

** Department of Anthropology, Quaid-i-Azam University Islamabad Email: sarfraz@qau.edu.pk

*** Department of Anthropology, Quaid-i-Azam University Islamabad Email: kamran.afridi1@gmail.com 
content here deliberately puts efforts to inculcate male-favored ideology in students. Gender is sensitive in the curriculum and the corresponding textbooks are one of the emerging issues that have attracted attention in various academic and policy settings. Present research on textbooks focused on the portrayal of women and how they have been stereotyped through various readings in the textbooks.

\section{Review of Literature}

A study was conducted by the World Federation of Teachers Union (as cited in UNESCO, 2004) to examine the position of both genders in textbooks. This report highlighted that the gendered ideology supports the sexiest representation in the support of men over the expense of women depiction in the textbook. The same speculation has been augmented by Lee and Collins (2009) in their study of the content analysis of English language textbooks and found an uneven representation of male and female. There were 489 pictures and out of that 278 were men's pictures and in comparison, women's images were small in numbers (only 94).

This view was further elaborated by Regueiro (2000) in a study of the same nature where she found out the poor representation of female musicians as compared to the overwhelming majority of males in the music textbooks. This can be seen across various countries as the above-mentioned three cases have identified the gender disparity in the textbooks. Elgar (2007) highlighted pictorial gender discrimination in the drawings where men are overrepresented as compared to the men throughout textbooks in Brunei. Not only in the formal textbooks but the verbal textbooks are also tilted towards men. This trend of underrepresentation of women in textbooks was also reported by Barton and Sakwa (2012). In line with the above-given review, Zagumny and Pulsipher (2008) found out the same issue in their study as well. They reported conventional gender disparity in the elementary level textbooks of Turkish schools wherein women's roles were portrayed as nurturing children, solely responsible for domestic matters, as well as facilitating their families in kitchen work. The issue of the underrepresentation of women prevails on the same lines in Pakistani textbooks as well and reported in the study of Agha, Syed, and Mirani (2018).

Anwar (1982) argued that out of 105 textbooks of different levels, 78 percent of books were authored by males while the authorship of females stood only 6 percent and the remaining books had been coauthored by both genders. All of the books represented male dominance through pictorial representations. Female charters were mainly represented inside the home by doing cooking, looking after the children, and performing all the domestic chores. The conventional gender discrimination was also reported by Shafi (2004) in his study of Urdu textbooks of various levels in all the four provinces of Pakistan. He further added that the worldview in the books is highlighted from men's vantage point of view while the female point of view has been suppressed and repressed. The same point of view was further highlighted by UNESCO's (2004) report about the representation of boys and girls in textbooks of grade one to three and reported the conventional representation of boys and girls, men and women.

Not only this, all indoor activities, roles, and sports were assigned to the females while outdoor activities, roles, and sports were assigned to males. Jafri (1994) further highlighted the positive connotation with the outdoor activities and professions while negative connotations were attached with the indoor activities and professions. Such role placement positioned men as dominant and women as subordinate. Wu and Liu (2015) research on china primary textbooks further strengthens the idea of role allocation through textbooks as research contended that gender bias is less persistent over the period yet the depiction of females as cleaning the house or engaging in household chores and male as reading, writing and watching TV conceive the idea of bias gender role allocation.

Gharbavi and Mousavi's (2012) research on Iranian high school textbooks asserted that the female part in pictorial representation in books is much lesser in ratio of men. Along with that, men are more visible in various occupations as depicted by textbooks comparing with females. Likewise, Hartman and Judd's (1978) research on TESOL books revealed that women were presented as emotional, fragile, and passive beings while portraying them as selfish and superficial and men as caring and helpful. The representation ratio of females to males was 27 percent to 73 percent in textbooks. The biased gender role allocation in textbooks culminates into inducing gender stereotypes in society. Gooden and Gooden's (2001) content analysis of children's picture books reported that several role allocation of male to female was 25 to 14 in children's picture books. Most males were pictured as not having any concern with household chores and females as up to conventional 
expectations were seen in their traditional role of taking care of home and children. Although the research figured that gender stereotypes are not as rampant as were in past but still obtrusive in children's picture books. Khurshid, Gillani, and Hashmi's (2010) study adds details to the representation of female images in textbooks and reported that male-oriented history has been taught to students and no female role can be observed in books. Further, females have been more concerned with religious activities as compared to males in textbooks.

Mattu and Hussain (2003) research contended that there is no noteworthy mention of female roles in the creation of Pakistan or any conspicuous contribution of women towards society. The Urdu textbooks portray the stories of males being decisive and females as impuissant and subservient to males. Islam and Asadullah's (2018) comparative content analysis of Malaysian, Indonesian, Pakistani, and Bangladeshi school textbooks findings unveil that the highest ratio of gender bias in textbooks has been found in Pakistani textbooks comparing to Malaysia, Indonesia, and Bangladesh schools' textbooks. The study also compared the Khyber Pakhtunkhwa (KPK) Board's and Punjab Board's English language textbooks of $9^{\text {th }}$ grade and shared the figures of female representation in KPK Board books and Punjab Board books that is $14 \%$ to $24 \%$ respectively. Hence it renders the idea that more the ratio of literacy rate is, the less the chances of the prevalence of gender stereotypes in textbooks.

\section{Theoretical Framework}

Innumerable books and literature give several theories on how children acquire their gender identities and one of these perhaps the most powerful is "sex role theory". According to the theory, sex roles are acquired through socialization managed by various factors such as the family, school, and peer groups. These roles are reinforced by repercussions associated with the compliance or noncompliance with such roles. The school is one significant actor that manages the socialization process of gender identities. Schools are institutions that are supposed to provide space for the overall growth and development of girls and boys. As such, they play a major role in gender socialization, by reinforcing the traditional values, attitudes, and stereotypes within the society through various teaching-learning practices. What is taught in schools through the curriculum is a vital part of schooling and consists of teaching and learning materials including textbooks, classroom practices, teachers, attitude and character examination procedures and language policy within the children grow up as female/male in the society. It serves as the strongest tool to transmit and or transform the culture, values, attitudes, and beliefs of the society to the learner (Stray, 1994; Durrani, 2008).

Textbooks play a very important role in the lives of children as gender socialization agents at an early age. These books play a crucial role in determining the children's worldview of what is appropriate for men and women in society. The textbook is an essential medium of power that shapes how children think about themselves and society several social scientists Mirza (2004), Özdoğru et al. (2004), Ullah and Skelton (2013) argue that texts and illustrations determine models of thought and offer preferred choices to children the books tell children what is right and wrong. What is beautiful and hideous? What can be achieved and what is out of reach, and hence shape children's identities.

\section{Materials and Methods}

Six major elements words (gendered pronouns), themes, paragraphs, number of characters, the glorification of gendered ideology, and pictorial representation related to traditional gender dichotomy were selected to collect data from the relevant textbooks to look into the social position of women in that. The textbooks of Urdu and English of grade 5th, 6th, and 7th were selected to investigate the sexist representation of the world through such books. Mixed inductive and deductive approaches were used to see gender stereotypes, such as a woman being passive, emotional, timid, delicate, dependent, sensitive, and under representative and marginalized.

Content analysis is a technique for systematically describing written, spoken, or visual communication. Through content analysis, one can examine and decipher the embedded message in the social communication-related objects such as written documents, children's books, television programs, photographs, magazines, and music recordings. Every type of social communication artifact carries a certain ideological message which serves the interest of those who produce and promulgate it through different means. Through the systemic interpretation of content, we can decipher hidden and apparent meaning carrying by every bit of information. 
Gender Construct: How is gender being portrayed in the textbooks, what kind of roles and attributes are being associated with both genders, and what concerned ideas the children are learning about gender and gender identity through course books.

Glorification: Is there any certain glorification of certain ideologies, institutes, roles, or roles present in the course books. If so, how do they impact the thought process of the children, and what purpose or, whose purpose does this glorification serve.

Language: What language is being used in the coursebooks? Is the language being used purposefully to create certain ideas or connotations in the minds of the children? Moreover, the language is used for easier understanding by the specific level of the children or not.

\section{Results and Discussion}

The findings of the review of the content of the books are in the sections according to the authorship and the theme/content of the books and how each subject has treated the images of masculinities. The pictures/illustrations in the books were reviewed to see how men and boys are represented as well as the text in each story to see how the identities of men and boys have been portrayed in the stories/lessons. The findings are shown in the following sub-sections: Authorship, Subject wise review of books, Urdu, and English.

\section{Authorship}

The books reviewed were developed according to the national curriculum and national style guide. The books have been published for the past few years before being repackaged and presented under the new management and supervision of textbook development principles and guidelines with new design and layout.

It is very interesting to note that most of the content has been authored by male scholars. Collectively there are authors of the content of poems and all out of these are male. This does not necessarily ensure gender-sensitive content; as male writers are under the influence of the same socialization as female. Similarly, all these books are also designed and edited by men and the management and supervision of the textbook creation process is also done by men. These textbooks present similar ideas of nationalism, public service, and citizenship. Masculinities presented in these books are generally physically strong and engaged in service to the nation. The protection of the passive feminine homeland/motherland under threat by external forces, and the protection of passive weak women are presented side by side as the duty and responsibility of men. This section proceeds with a subject-wise gender analysis of each subject and then concludes with an overarching analysis of themes and masculinities promoted by these textbooks. Protection of the female motherland and protection and help of women all are the job of men.

\section{Urdu}

Overall, the world presented within these books seems to have very few women. Even narratives on schools are dominated by male characters; the lesson describing an exemplary student depicts male students in a boy's only school with a male teacher. Only in some cases, there is a balance created by giving a story about a girl or a woman who was a high achiever e.g. story of Fatima Jinnah, but generally, these are fewer in number than the stories and lessons about boys and men. Thus, such women are implicitly shown as exceptional, and separate from the norm of womanhood.

All Urdu textbooks are dominated by pictures of men and boys. While there are a few pictures in each book that show both boys and girls, or entire families with men, women, girls, and boys, these are far fewer in number. The visual absence of women again implicitly reinforces the social norm that women are to be seen primarily concerning their male relations or counterparts, and not as individuals who can stand alone as independent agents within society.

A few pictures show people performing certain activities or doing their professional work. When things are related to boys' activities, they are mostly playing games such as football, cricket, hockey, etc., or are either reading or working on the computer. Where men are shown in professions, they are involved in work that requires technical understanding or skills, physical strength, or finance. Girls are shown playing hide and seek, rope skipping, crying and women are shown in a few professions only i.e. teaching, nursing, or working in the home. Once more, budding masculinities are expressed through the physical exertion of the body through sport and play.

\section{5th standard Urdu book}

The analysis of Punjab textbook board of 5th standard Urdu. The book, as anticipated, carries gender bias in many chapters. First, there are 5 heroes presented in the book, and out of all only one female 
hero is mentioned in the book. Prophet Muhammad, Hazrat Usman, Major Tafel Shaheed, and scouts are presented as heroes of the country. From the female side, only Fatimah Jinnah's contribution is discussed regarding her brother Quaid-i-Azam. Secondly, the major gender bias is embedded in gender pronouns. Our syllabus has always carried gender-inclusive pronouns and is inclined towards the use of male inclusive gender pronouns. Gender-neutral pronouns or female inclusive gender pronouns have always been brushed aside. Urdu language has more gender-inclusive pronouns than English. The language segregated males and females in every place through gender pronouns. The dilemma, however, is that male inclusive gender pronouns are dominant in our syllabus. In most of the chapters, the end of the chapter has carried a student picture that is of a male child as well. Pictorial representation and character sketching in different stories are all of male dominant.

In the third chapter, the story of Hajra-e-Aswad revolves around only males of ancient tribes. Even angels are manifested as males and male pronouns are used for them. Same with the case of Muslims as the last line of the chapter depicted male version of Muslims only. In the activities assigned at the end of the chapter for students, only male inclusive pronouns are used to address students. Chapter 4, glorify humanitarianism, and Hazrat Usman, a male philanthropist is depicted as the hero of the Muslim nation and an exemplary humanitarian. At the end of the chapter, the male child picture has shown an activities section.

Chapter 5 portrayed the image of the female hero, Fatimah Jinnah. The chapter starts with her introduction concerning her brother Quaid-i-Azam Muhammad Ali the founder of Pakistan. There On page 19 in the third line of the chapter marked her major contribution that "She had supported her brother at every place during Pakistan movement". On the same page, it is written that she loves her brother. That implies that the major contribution of our female hero is that she supported, loved, and was obedient to her male-dominant relation.

On page 19, major features of her personality are highlighted with the words "she had the art of managing things (saleqamand). She always wore a clean dress" The ideal woman picture is the one who has the art of managing things smoothly and to be clean. So, a woman is expected to take care of domestic things with great care (saleqamand) and no male hero is labeled with such word in the book.

Chapter 12 is titled "my village, my home" in which a sketch of village life has drawn. In the whole chapter, females are discussed in only three lines and all other chapters have contained maledominant activities. On page 46, females have shown offering prayer at home. On page 47, shops of female bangles and Mehendi (henna) have shown and on 48, a marriage scene is presented in which females were singing and clapping. So the only job female do is offer prayer at home, wear bangles, and singing and clapping at home. On page 47, farming was portrayed as a major earning source of village people and only male farmers were discussed in the chapter ignoring the role of female contribution in farming. On the same page, a sketch of village social events has portrayed. Females were supposed to wear bangles and males were participating in games that requires strong physical force like kabaddi (wrestling) rasakushi (Rope pulling) and football.

Chapter 17 discussed scout movement with male scout picture at top of page. Children are encouraged to join scout and girl guides to help people. Girls guide is only discussed in two lines of the chapter and all other chapters provided information on male scout and their qualities. Chapter 19 titled "our environment" raises awareness of keeping the environment clean. This is the only chapter where the two main characters are female, daughter, and mother. However, the second line of the chapter presented a scene of the mother coloring her dupatta, reveals the inevitable relation of dupatta and eastern women. Chapter 22 raises awareness in children regarding terrorism. The main character is again a male child who depicted bravery and helped police to engage terrorists.

\section{6th standard national book foundation Urdu Book}

Chapter 3rd titled "reward of kindness" demonstrated male figures of Abdullah bin Mubarik and shoemaker and their epitome of kindness and virtue. The book discussed four male historical characters, Abdullah Bin Mubarak, William Kakston, Major Shabir, and Sheikh Saadi, and only one female figure, Fatima Jinnah. Chapter 8 is a satire poem on the "condition of Muslims during fasting". The male character of the poem was frustrated because of fasting and he is suggesting his wife and children be away from him. This conceives the idea that the male figure of home is a dominant and authoritative one.

Chapter 11 is titled "hard work" with a picture of two males doing labor. The hard work thus associated is with only males of society. Chapter 12 depicts the image of Fatima Jinnah and her 
contribution to the Pakistan movement. The qualities of Fatima Jinnah on page 35 are presented in these words "she was decent, elegant, loyal and has etiquettes". The idea presented here is that the female ideal should be decent elegant and most importantly loyal. The element of loyalty has always been attached to females in our curriculum. On page 36, the mother is encouraged to look after her kids and teach them. The next line also encouraged the role of the father but the sequence places the mother's role foremost in the upbringing of children. Chapter 13 describes the sports of children. The two major games kabaddi and shape are discussed. Kabadi is represented as a game of boys which needs maximum physical force and strength. Shatapo an indoor game only requires little physical effort and is labeled as a girls' game. In this way, only males are encouraged to use physical force and strength and to be resilient.

\section{7th standard national book foundation Urdu book}

Chapter 2 presents Naat of Prophet Muhammad. Page 7, 1st line is "every man got secret of hard work". Instead of using gender-neutral pronouns like human, man is used to address people. Chapter 3 of a book titled "difference between urban and rural life" presented the character sketch of a boy and his male cousins. In the last paragraph of page 11, the female household was shown putting food on the table that asserts the idea that the female household cooks and serves food to the family. Page 12 presented the role of women in society in this line "rural women do all domestic chores with their hands". In the last line of the same page, the male role in society was demonstrated as "my father teaches in college, my one uncle does the job in an office and other uncle works in the workshop." All the outdoor earning jobs were assigned to male and females only job is supposed to be taking care of the home.

Chapter 4 teaches the importance of discipline by referring to the male figure of Quaid-iAzam as the epitome of discipline. Chapter 5 sheds a light on the invention of the airplane by white brothers. Another glorification of male scientists presented in the syllabus. Chapter 11 presented the story of the earth in a female voice. The association of earth with females is maybe because earth is associated with motherly characters of loving, caring, and gentle. Earth is feminized because it is seen as possessing the same qualities as women like being domestic, pious, moral, pure, gentle, kind, graceful, simple, and beautiful.

Chapter 17 discussed the role of females in the Pakistan movement. On page 94, it is mentioned that Quaid-i-Azam encouraged women to take part in the Pakistan movement. The basic initiative behind the role of females was again a male. On page 95, the contribution of Fatima Jinnah is mentioned in these lines "she devoted all her life for her brother. She always supported him". The major contribution of the female hero is considered her devotion to the male figure. Several female activists have been named in the chapter and the last paragraph of the chapter illustrated the fact that these female activists encouraged males to work of their full devotion. Chapter 18 paid attention to philanthropy and again male stories and male figures are presented as philanthropists. Chapter 19 paid tribute to the life of martyrs in the 1965 Pak-India war. Major Azizi Bhatti and Major Shafqat Baloch were presented as national heroes. On page 128, the activity section contains the following two sentences depicting gender roles inculcated in the curriculum. "A labor got fainted due to working in severe hot weather". "The clothes of a mother caught fire while she was working in the kitchen."

The male figure was working outside and doing labor while the female was working in the kitchen as only women are supposed to work in the kitchen. Chapter 23 is a tributary poem on Quaidi-Azam. A male savior of nation and chapter 24 has again presented male military hero of the nation, Sawar Muhammad Hussain Shaheed. The last chapter 25 of the book is a poem about helping people with a picture of a male child helping elder women. Male dominance in the syllabus, to sum up, is evident. Male characters in stories, male heroes of the nation, and male Muslim heroes are ruling over our syllabus.

\section{English books}

6th Standard English book: The analysis of the National textbook of 6th Standard English unveils many imprinted gender bias. Female share in pictorial representation is much less than boys. The activity section in all chapters contained a picture of the boy. Character sketching in different chapters is also male dominant. The first chapter titled "A misunderstanding" has the characters of father, mother, and daughter. Father is depicted as a man who is not in a hurry and mother is the one who asks too many questions. Though it is required for females to have patience, but males are always portraying as more patient in worldly affairs while females are considering grouchy and curious about 
everything. On different pages like pages 12 and 13, while discussing gender, males have mentioned before females. e.g. "either male or female" "man or woman". Page 31 mentioned, "why do you like him or her" and in so many other places "him" always comes before "her". Sequence and ordering of words play a potent role in influencing the learning of children as repeated things or things mentioned first put more influence over the mind of children. On page 15, the words "blue boy" have mentioned depicting blue as masculine color. Page 17 mentioned some words rhymes where wife comes before knife and ladies comes before monkeys and donkeys. Coincidence or demonstration for a particular purpose?

Page 22 asked about the general opinion that "is it important for girls to read and write? Give reasons". The question depicts society's reality where females must answer the question that why they need education. For males, it is obvious. Page 28 Girls playing badminton illustrate the fact that badminton is always considered to be a sport for girls because games can be played indoors and hence "safe" for girls. However, classifying a sport as "feminine" is disrespectful for players of those sports. Page 47 exercise part again depicted female-male roles through certain words and sentences. "He is a tour guide" and then "She is in the room". The daily life manifestation in content revealed genderassigned roles as well. Page 51 associated earth with mother by implying the idea that "like a mother, it gives us everything". So, the mother in our society is expected to give every sacrifice for their children. The idea of giving everything associated with the mother confine women to the limited role of sacrificing and always giving. Shopping has always been categorized as a female job and page 54 is consistent with this reality "Mother has a clothing bag for shopping".

Chapter 6 titled "a bus journey" portrayed a boy sketch, tender-hearted, and well-mannered. Page 72 activity section contains two lines picked from the lesson. "It is the mother who stays at home, not Hamid. Second "The woman was weak, but boys were strong". All the images inclined towards making gender roles. Chapter 8 captures a sports day at school. Page 83 pictorial presentation illustrated two boys playing football. A game that required physical force and outdoor places to play is categorized as a "masculine" game. Page 85 has sketched a tallboy. In children's syllabus, it has particularly noticed that male is always portrayed as "tall" as it contains the idea that tallness must be the dominant feature of male. There is no picture in the book where the female character is presented taller than the male character. Page 123 of the book contains three sentences depicted assigned male and female roles in society. Sentence one "Ali said to Asma, "you make tasty soup" Sentence two Huma said to Mehru "can you make vegetable soup?" Sentence three "vegetables are brought by Ali". Association of cooking with females and purchasing with males demonstrate the gender assigned roles in our society and regurgitation of these roles in content make sure that children could learn and act according to assigned roles without any room for deviance.

\section{7th Standard English book}

Page 22 has taught children about vowels by mentioning "an honest man" in the book which depicts two realities. Association of positive traits with male gender and secondly, using man for describing any social reality. Page 23 has the sentence "Aslam is a tall boy". As it is mentioned previously that tallness has always been associated with males in the whole content. Page 45 of the book again repeated the fact "He is taller than me". Page 33 mentioned these words separately in a sequence; "father, gentleman, husband". The sequence depicted the gentle nature of father and husband in society. Page 79 mentioned those words closely linked with each other like big house, green tree, and again "a tall boy". This demonstrated how closely the feature of tallness is considered relatable with masculinity.

Page 53 contained images of "witches" and the image only has women with black shawl and black cap and hence no link with the real image of witches. The question arises as that why it was necessary to give children an idea about witches and how the teacher would explain the figure to children and what impact it will create on the mind of students about female witches? Surely, not positive. Depiction of kindness and bravery with males in these books and witch figures of females would promulgate gender stereotypes and misconceptions. Chapter 6 titled "The Echoing Green" page 55 contained two images of children playing games. One is of boys playing cricket and the other is of girls playing the traditional game "kikli" in which girls only move in circles with partners by joining hands. The categorization of games as "masculine" and "feminine" is again demonstrated in content. Chapter 7 mentioned women's role in development and hence an important bridge of linking women 
representation with content but no proper contribution of any woman is mentioned in the chapter except Fatima Jinnah.

The chapter only enlisted several professions females are involved in but how they are contributing to the development sector has shunned. Chapter 8 story about a dentist contains a pictorial representation of a male dentist. Association of gender-neutral professions with male genderinclusive depiction can be seen. Page 70 has the sentence "my mother cook meals". The allocation of work to specific gender is evident. The same page has two words in the activity section arranged in a sequence of one after another "beautiful and lipstick". The association of beauty with female cosmetic product lipstick endorses the mindset that appreciates female makeup to enhance their beauty. Page 95 has two sentences in the activity section again depicting assigned roles of females in society. "She cooked meal" "she was ironing the clothes" representing an image of a female busy in domestic chores.

\section{Conclusion}

This study has unmasked gender discrimination and gender bias inculcated in the syllabus of textbook boards. Gender roles have been assigned through certain narratives and discourse. Our syllabus is the major carrier of these gender roles and susceptible to carrying, transferring, perpetuating, and incorporating these gender biases in the mind of children. Gender stereotypes intruded in books and providing less room for readers to comprehend the world from their reality. Gender bias in content is evident through content analysis.

The values that describe a masculine culture include:

- $\quad$ Maximum emotional and social role differentiation between the genders.

- $\quad$ Men should be and women may be assertive and ambitious.

- Hegemony of male in pictorial representation.

- $\quad$ Portrayal of Male heroes only in all over the syllabus.

- $\quad$ Admiration for the resilient, tall, powerful males.

- $\quad$ Men associated with education wisdom foresight etc.

- $\quad$ Domination of male in different character sketching in books.

- $\quad$ Segregation of games into male-female categories. Strong physical strength imperative for outdoor games has been considering as male-centered games and indoor games have associated with females.

- $\quad$ Male gender-inclusive pronouns have been used even at gender-neutral places.

- $\quad$ Sacred figures like Allah and Angels have been addressed through male inclusive pronouns.

- Bravery, courage, and boldness are presented as masculine characteristics.

- $\quad$ Few women in elected political positions; separate spheres of performance public sphere for men; businesses, private sphere for female.

- $\quad$ Association of domestic chores with females and outdoor work with males.

- $\quad$ Gender-neutral professions are represented as male professions.

The text represents dominant masculine culture. Female voices are unheard or deliberately brushed aside in the syllabus. This distorted text imparts male chauvinism and gender inequity in students. The rampant misogyny prevailing in our society is interwoven with gender beliefs stem from perverted syllabus. The images of masculinity portrayed in the books will affect boys by which they conceive possible masculinities; furthermore, such imagery also affects girl's perceptions about prevalent masculine behaviors and how they are expected to behave in response to or concerning such masculinities. These books play a potent role in determining the children's worldview of what is appropriate for men and women in society. Patriarchal culture nullifies women's contributions towards society under the puissance of men. Men are prompt by their families, and school to be competitive, tough, and irascible. It stresses the ascendancy of the male worldview and disparages all womencentered characteristics and activities. The content diffuses the male-centric approach through language by employing male inclusive pronouns for describing abstract concepts and depicting all social lessons through male-centric stories. The androcentric approach in textbooks emphasis masculinity being prerogative, vigorous and brawny while vitiating the entire narrative of femininity by presenting women as delicate, frail, and sentimental. 
References

Agha, N., Syed, G. K., \& Mirani D. A. (2018). Exploring the representation of gender and identity: Patriarchal and citizenship perspectives from the primary level Sindhi textbooks in Pakistan. Women's Studies International Forum, 66, 17-24.

Anwar, M. (19 82). Images of male and female roles in school and college textbooks. Women's Division Government of Pakistan, Islamabad.

Barton, A., \& Sakwa, L. N. (2012). The representation of gender in English textbooks in Uganda. Pedagogy, Culture \& Society, 20(2), 173-190.

Durrani, N. (2008). Schooling the other: The representation of gender and national identities in Pakistani curriculum texts. Compare: A Journal of Comparative and International Education, 38(5), 595610.

Elgar, A. G. (2007). Science textbooks for lower secondary schools in Brunei: Issues of gender equity. International Journal of Science Education, 26(7), 857-894.

Gharbavi, A., \& Mousavi, S. A. (2012). A Content analysis of textbooks: Investigating gender bias as a social prominence in Iranian high school English textbooks. English Linguistic Research, 1(1), 4249.

Gooden, A. M., \& Gooden, M., A. (2001). Gender representation in notable children's picture books: 1995-1999. Sex Roles, 45(1), 89-101.

Hartman, P. L., \& Judd, E. L. (1978). Sexism and TESOL materials. TESOL Quarterly, 12, 383-393.

Islam K. M. M., \& Asadullah M. N. (2018). Gender stereotypes and education: A comparative content analysis of Malaysian, Indonesian, Pakistani, and Bangladeshi school textbooks. PLoS ONE 13(1), e0190807. https://doi.org/10.1371/journal. pone.0190807

Jafri, R. (1994). Gender bias in Pakistan school textbook. Lahore: Aurat Foundation.

Khurshid, K. I., Gillani, G. M., \& Hashmi. A. (2010). A Study of the representation of female image in the textbooks of English and Urdu at secondary school level. Pakistan Journal of Social Sciences, 30(2), 425-437.

Lawson, K. M., Crouter, A. C., \& McHale, S. M. (2015). Links between family gender socialization experiences in childhood and gendered occupational attainment in young adulthood. Journal of Vocational Behavior, 90, 26-35.

Lee, J. F. K., \& Collins, P. (2009). Australian English-language textbooks: the gender issues. Gender and Education, 21(4), 353-370.

Mattu, A., \& Hussain, N. (2003). Gender bias and stereotypes in school texts. In A. Mattu and N. Hussain (Eds.), The subtle subversion: The state curricula and textbooks in Pakistan (pp. 91-98). Islamabad, Pakistan: Sustainable Development Policy Institute.

Mirza, M. (2002). Gender Analysis of School Curriculum and text. Islamabad: UNESCO, Islamabad.

Özdoğru, A. A., Aksoy, G., Erdoğan, N. and Gök, F. (2004). Content analysis for gender bias in Turkish elementary school textbooks. Paper presented at the 16th annual Ethnographic and Qualitative Research in Education conference. June, Albany, NY.

Regueiro, P. D. (2000). An analysis of gender in a Spanish music textbook. Music Education Research, 2(1), 57-73.

Shafi, S. (2004). Evaluation of primary level Urdu textbooks from the perspective of women. Lahore: Aurat Foundation.

Stray, C. (1994). Paradigm regained: Towards a historical sociology of the textbook. Journal of Curriculum Studies, 26(1), 1-29.

Ullah, H., \& Skelton, C. (2013). Gender Representation in the Public sector schools textbooks of Pakistan. Educational Studies, 39(2), 183-194.

United Nations Educational, Scientific and Cultural Organization. (2004). Gender analysis of school curriculum and textbooks. Islamabad: United Nations Educational, Scientific and Cultural Organization.

Wu, H., \& Liu, W. L. (2015). Gender representation in primary English textbooks in mainland China 1978 to 2003. International Journal of Humanities and Social Science, 5(6), 116-129.

Zafar, F. (2005). A Gender review of Education in the Punjab: Society for the Advancement of Education (SAHE).

Zagumny, L., \& Pulsipher, L. M. (2008). 'The races and conditions of men': Women in nineteenth-century geography school texts in the United States. Gender, Place \& Culture: A Journal of Feminist Geography, 15(4), 411-429. 